\title{
HIV infection and psychiatric
} illness

\section{B Owe-Larsson, L Säll, E Salamon, C Allgulander}

Karolinska Institutet, Department of Clinical Neuroscience, Section of Psychiatry at Karolinska University Hospital Huddinge, Stockholm, Sweden

\begin{abstract}
Objective: To review the clinical features and current knowledge on the treatment of psychiatric symptoms and disorders in patients with human immunodeficiency virus (HIV) infection. Method: We searched the PubMed database combining HIV/AIDS with different keywords for psychiatric diagnoses and symptoms (e.g. depression, mania, anxiety, psychosis, dementia, substance abuse) and for psychopharmacological treatment. The years covered by these searches included 1980 to 2008 . Results: Patients with HIV infection are at an increased risk of psychiatric illness. Major depressive disorder and subsyndromal depressive symptoms, as well as anxiety disorder and substance abuse are more prevalent among HIV infected individuals than among the general population. HIV-associated neurocognitive disorders (HAND) are common among HIV patients, and HIV-associated dementia (HAD) is a serious condition during the acquired immune deficiency syndrome (AIDS) stage of HIV disease. Secondary mania and psychosis might be the first clinical symptom of HIV dementia. The introduction of highly active anti-retroviral therapy (HAART) has resulted in significant decreases in morbidity and mortality for HIV infected patients. HAART has also decreased the incidence of $\mathrm{HAD}$, but does not give complete protection from this condition. The utility of psychotropic medications in HIV patients has not been studied sufficiently as a basis for guidelines, and more controlled trials are needed. Conclusion: Psychiatric illness is common in HIV infected individuals, and underlines the importance for screening not only for cognitive impairment but also for co morbid mental disease in HIV-positive patients. Further studies of the neuropsychiatric complications during HIV disease and the use of psychotropics under these circumstances are clearly needed. A better understanding of the pathogenesis of HAD is essential to identify additional therapeutic strategies for prevention and treatment of this neurodegenerative disease. Studies are also needed for optimizing effective utilization of antiretrovirals into the CNS. Mania and psychosis secondary to HAD may be used as an indicator to initiate HAART, irrespective of CD4 count. Further research on the utility of HAART in the treatment of such acute neuropsychiatric symptoms associated with HIV infection should be initiated.
\end{abstract}

Key words: HIV-associated neurocognitive disorders; HIV-associated dementia; AIDS; Psychosis; Secondary mania; HAART

Received: $23-05-2008$

Accepted: 17-06-2008

\section{Introduction}

HIV is a ribonucleic acid (RNA) retrovirus that is the causative agent for AIDS. HIV belongs to the Lentivirus genus in the family Retroviridae, characterized by a replication cycle in which the viral RNA is reverse transcribed into a DNA proviral form that is integrated into the host cell genome. The retrovirus is composed of two copies of single- stranded RNA that codes for the virus's 9 genes. The RNA is non-covalently linked to the

\section{Correspondence:}

Dr Björn Owe-Larsson

Karolinska Institutet, Department of Clinical Neuroscience,

Section of Psychiatry at Karolinska University Hospital Huddinge,

SE-141 86 Stockholm, Sweden

email: Bjom.Owe-Larsson@ki.se core proteins, which in turn is surrounded by a viral envelope, which enables the virus to enter cells by binding to a specific cellular receptor located on the surface of cluster of differentiation 4 (CD4) cells. ${ }^{1}$ A few years after the discovery of HIV-1, a second virus, HIV-2, was found in West Africa. HIV-1 and HIV-2 differ regarding their content of the genome, resulting in lower AIDS rates in HIV-2 infected individuals. ${ }^{2}$ Once exposed to the body, the HIV virus antibodies may be detected after an acute flu-like illness, and then proceeds to infect specific cells of the immune system during an asymptomatic period that may last for years. In order to enter a cell, HIV must bind to CD4, typically found on T lymphocytes, blood monocytes, macrophages and some dendrite cells, and subsequently to one or a combination of several possible chemokine co-receptors, usually CCR5 and CXCR4.3,4 The late 
stage of HIV infection, AIDS, begin after HIV has replicated itself into the T4 helper cells in the lymphatic system, over time causing a severely affected immune system. This stage is characterized by a generalized lymphadenopathy and AIDS related complex (ARC), leading to an immunosuppressed state with manifestation of a variety of opportunistic infections including cytomegalovirus (CMV), Epstein Barr virus (EBV), herpes simplex virus, John Cunningham (JC) virus,

cryptococcosis, Pneumocystis carinii, toxoplasmosis and tuberculosis. , $^{1,-7}$ In addition, patients may develop previously uncommon or unknown tumours, the most common of which are non-Hodgkin's lymphomas and Kaposi's sarcoma. ${ }^{1,5}$

The existence of a specific infection of the CNS became apparent later and was confirmed by viral detection within the nervous tissue, together with the finding of multinucleated giant cells (MGC), a result of virus-induced fusion of infected macrophages. ${ }^{8}$ Characteristic neuropathological findings at autopsies in $\mathrm{HAD}$ are encephalitis with reactive astrocytosis, multinucleated giant cells, activated microglia, infiltration of monocytoid cells, myelin pallor and vacuolar myelopathy. ${ }^{1,5,9}$ These abnormalities are commonly seen within the central white matter, frontal cortices, basal ganglia, thalamus and brain stem. ${ }^{10}$ The myelopathy usually progress in parallel with $\mathrm{HAD}$, but occasionally develops before or without dementia, and manifests as a progressive spastic paraparesis with sensory ataxia. ${ }^{11}$ According to one model (the Trojan horse hypothesis), HIV enters into the CNS by migration of infected peripheral blood mononuclear cells through the blood brain barrier (BBB), and then resides primarily in perivascular macrophages and microglia. ${ }^{9}$ However, it is also possible that cell-free virus penetrates the brain by directly crossing the BBB. ${ }^{3,9}$ Various groups have found evidence of HIV infection also in astrocytes and oligodendrocytes, but neurons do not seem to be infected. ${ }^{9}$ However, it has been reported that neural progenitor cells are permissive to HIV virus. ${ }^{12}$ In macrophages/monocytes and microglial cells, HIV establishes a productive infection and is the source of transmission in CNS, while in other cells, as astrocytes, HIV only establishes a persistent, rather than productive infection. ${ }^{1}$

HIV seems to penetrate into the CNS soon after the initial systemic infection in the periphery. ${ }^{9}$ However, there is little evidence that primary viral seeding result in a permanently productive infection within the CNS. During the period of immunodeficiency, i.e. AIDS, viral replication in the CNS is quite robust. The origin of this viral population is still unclear; it may emerge as the result of waves of neuroinvasion during the course of infection, or it could be the result of low levels of replication in a reservoir of microglia. ${ }^{3}$

Since HIV infection within nerve cells has never been conclusively demonstrated, indirect mechanisms seem to explain the neuronal damage in HAD. By activation or infection of microglia, macrophages and astrocytes, HIV induces activation of inflammatory mediators, cytokines, chemokine receptors, extracellular matrix-degrading enzymes, and glutamate receptor-mediated excitotoxicity. Furthermore, HIV proteins, including the HIV envelope glycoprotein 160 (gp 160), which is cleaved into two non-covalently, associated products (gpl20 and gp41), and the HIV transactivator protein Tat, have the potential for neurotoxicity. All these factors can disturb neuronal and glial function, and may act in concert to promote neurodegeneration and neuronal death ${ }^{9}$, which in turn leads to modification of synaptic architecture of affected areas. The apparent ability of HIV to interfere with neural progenitor cells might also impair renewal mechanisms and neurogenesis in the CNS. ${ }^{13}$

\section{HIV-associated dementia (HAD)}

The involvement of the CNS was reported early in the AIDS epidemic. The concept of neuro-AIDS evolved between 1983 and 1988. ${ }^{14-18}$ Separate and overlapping diagnostic terms were created to define the psychiatric and neurological clinical symptoms related to HIV infection, collectively designated the AIDS dementia complex (ADC) $)^{15,18}$, HIV-associated dementia (HAD) ${ }^{19,20}$, HIV encephalopathy ${ }^{21}$ or simply HIV dementia. ${ }^{8,21,13}$ A milder form of HIV-associated cognitive impairment is termed minor cognitive motor disorder (MCMD) ${ }^{19}$, or according to the latest research proposal, HIV-associated mild neurocognitive disorder (MND). ${ }^{20} \mathrm{HIV}$ encephalitis (HIVE) is the pathological correlate of $\mathrm{HAD}$, and should not be used to describe the clinical syndrome. ${ }^{21}$

HIV has a tendency to affect subcortical regions in the CNS. HIVE is particularly found in the basal ganglia and central white matter, but the neocortical grey matter and to a lesser extent the brainstem and cerebellum are sometimes involved, and HIVE may be present in any area of the brain. ${ }^{6}$ Magnetic resonance imaging (MR) typically demonstrates both cortical and central atrophy and corresponding ventricular enlargement. ${ }^{11}$ In addition, characteristic confluent signal abnormalities within the deep white matter can be found. These findings represent increased water content and can be reversed with HAART. ${ }^{21}$ The severity of HIVE varies from mild cases to severe states with widespread inflammation and numerous giant cells. These variations could explain the observed range of clinical symptoms. ${ }^{6}$ The presence of HIVE shows a degree of correlation with HAD, but this is not an absolute association, and there are occasional cases with evidence of HIVE at autopsy but no clinical history of dementia. ${ }^{6}$ The clinical features of HAD usually exhibit the hallmarks of a subcortical dementia, and are characterized by three key features: cognitive impairment, behavioural abnormalities and disturbed motor function. 3,5,8,11,15,22 Symptoms may include psychomotor slowing, apathy and motor disorders as bradykinesia, tremor and postural and gait abnormalities (e.g. stumbling, tripping). These symptoms are also found in other well-defined basal ganglia diseases such as Parkinson's disease, and alterations in the nigrostriatal dopaminergic system have also been shown in HAD. ${ }^{23}$

The initial cognitive symptoms often include memory loss, mental slowing, reading and comprehension difficulties and apathy. ${ }^{11}$ The typical mental and neuropsychiatric deficits of $\mathrm{HAD}$ are characterized by memory loss (selective for impaired retrieval), impaired ability to use acquired knowledge, personality changes (apathy, irritability, inertia), and general slowing of thought processes. ${ }^{11}$ Further neuropsychiatric sequels in HIV-positive patients may include deficits in attention, concentration, language, executive skills, information processing, and subsequently aspects of motor functioning. This may also be accompanied by depressive withdrawal, impulsivity, manic symptoms, organic psychosis with paranoid features, sleep changes (hypersomnia), impaired judgement, disorientation, or even delirium. .,24 $^{5}$ 
Considerable individual variability of presenting symptoms has been reported. ${ }^{15} \mathrm{HAD}$ may be difficult to distinguish from depression in some cases, especially the initial symptoms which can be subtle and overlooked. ${ }^{5,11}$ Other conditions that may mimic HAD include opportunistic infections affecting the CNS and primary CNS lymphoma. ${ }^{11}$ CSF sampling and imaging studies should therefore be performed in the diagnosis of HAD to exclude opportunistic infections and other causes of cognitive impairment. ${ }^{21}$ Important tests of CSF include cell count and protein, culture (particularly mycobacterial and fungal), cryptococcal antigen, and polymerase chain reaction testing for toxoplasma, cytomegalovirus, Epstein Barr virus, John Cunningham virus and herpes virus.

As presented above, there might be significant cognitive deficits in cases of both asymptomatic HIV and AIDS, but these deficits are small in early stages of HIV and increase in the later phases of the illness. Motor functioning, executive skills, and information processing speed were among the cognitive domains that showed the greatest decline from early to later stages of HIV according to a meta-analysis made by Reger and colleagues. ${ }^{24}$ Early psychomotor slowing may predict the development of HIV-associated brain disease. ${ }^{25}$ and autopsyverified HIVE, and precedes clinical HAD by $1-2$ years. ${ }^{26}$ However, the predictive value of quantitative motor test abnormalities for evolving cognitive impairment needs further delineation and testing. ${ }^{20}$ The severity of symptoms varies, however; in a study of 28 patients with early stage HIV infection (CD4 >280 cells $/ \mathrm{mm}^{3}$ ), not receiving HAART, and followed during 7 years, no major deterioration in the neurological, psychological performance, neurophysiological or neuroimaging examinations could be revealed. ${ }^{27}$ Elevated HIV RNA in CSF may predict subsequent progression to neuropsychological impairment. ${ }^{28}$

Amyotrophic lateral sclerosis (ALS)-like syndrome can occur in association with HIV infection ${ }^{29}$, as well as sensory neuropathies ${ }^{30}$, and neuromuscular syndromes as distal symmetric polyneuropathy (DSP), myopathy and HIVassociated neuromuscular weakness syndrome. ${ }^{31}$

$\mathrm{HAD}$ follows a course of decreasing functional ability at a variable rate, resulting finally in a mute and paralyzed patient with severe, global dementia, often accompanied by vacuolar myelopathy and sensory neuropathies. ${ }^{11}$ The average survival with HAD is 6-9 months in untreated patients. ${ }^{5,8} \mathrm{HIV}$ is probably the leading cause of dementia in people less than 40 years of age. ${ }^{32} \mathrm{HAD}$ constitutes an independent risk factor for death due to AIDS. ${ }^{9}$

In 1991, the Working Group of the American Academy of Neurology AIDS Task Force established diagnostic criteria for the diagnosis of HAD. ${ }^{19}$ According to these criteria, $\mathrm{HAD}$ requires a person to: 1) exhibit objective cognitive impairment, verified with standardized neuropsychological tests, in at least two domains (e.g., memory, attention, language, processing speed), 2) show impairment in performing activities of daily living (ADL), 3) experience either motor impairment or impaired emotional control or changes in social behaviour, 4) the pattern of cognitive impairment does not meet criteria for delirium (e.g., clouding of consciousness is not a prominent feature) and 5) exclusion of alternate neurological disorders through the use of laboratory studies, including CSF analysis when appropriate, and brain imaging by computed tomographic scanning or magnetic resonance imaging (MRI). ${ }^{19}$ They also defined a less severe condition called minor cognitive motor disorder (MCMD). The essential features of MCMD were a history if impaired cognitive/behavioural function in two areas, causing mild impairment in work or ADL, does not meet criteria for HAD or HIV-associated myelopathy, and cannot be attributed to other etiologies. ${ }^{19} \mathrm{MCDC}$ has been demonstrated to affect several important areas, including medication adherence and driving ability ${ }^{11}$, and seems to have a high predictive value for subsequent detection of HIVE at autopsy.11

Some issues of the 1991 criteria may restrict their applicability. ${ }^{20}$ The number of domains of impairment that should be examined for diagnosis was not clearly defined; the degree of cognitive impairment was not fully specified; and there appeared to be some overlap between the criteria for mild HAD and MCMD. Finally, the classification did not admit mild forms of cognitive difficulties which had not developed to the point of interfering with everyday functioning. ${ }^{20}$ Therefore, an updated research nosology for HIV-associated neurocognitive disorders (HAND) was published 200720, separating HAND into three categories:

1. HIV-associated asymptomatic neurocognitive impairment (ANI) is defined by l) acquired impairment in cognitive functioning, involving at least two ability domains at least 1.0 standard deviation (SD) below the demographically corrected means (the neuropsychological assessment must survey at lest the following abilities: verbal/language; attention/working memory; abstraction/executive; memory - learning and recall; speed of information processing; sensory-perceptual, motor skills), 2) the cognitive impairment does not interfere with everyday functioning, 3) the cognitive impairment does not meet criteria for delirium or dementia, and 4) there is no evidence of another pre-existing cause for the ANI. ${ }^{20}$

2. HIV-1-associated mild neurocognitive disorder (MND), which is similar to the MCMD described in 1991, but more precisely defined: 1) an acquired mild-to-moderate impairment in cognitive function documented by a score of at least 1 SD below demographically corrected norms on test of at least two different cognitive domains, 2) the cognitive impairment interferes, at least mildly, with activities of daily living, 3) the impairment does not meet criteria for delirium or dementia, and 4) the impairment is not fully explained by co morbid conditions. ${ }^{20}$ Such a patient may show mild impairment in concentration, attention or memory, and for example complain of reading difficulties and being easily distracted due to poor concentration level.

3. HIV-1-associated dementia (HAD) requires according to these criteria 1) acquired moderate-to-severe cognitive impairment, documented by a score at least 2 SD below demographically corrected normative means in at least two different cognitive areas, 2) marked difficulty in ADLs due to the cognitive impairment, 3) the impairment does not meet criteria for delirium, and 4) the impairment is not adequately explained by co morbid conditions. ${ }^{20}$ Such a patient may for example show symptoms as delayed speech output, poor emotional and thought content with lack of spontaneity and social withdrawal. 
Consequently, according to this nosology, the presence and degree of neurocognitive impairment constitute the fundamental criteria for diagnosis, while other criteria, e,g motor disorders and emotional or personality changes are considered corroborative information. The criteria allow qualification of the progression of HAND according to activity. Determination of neurocognitive impairment should be based on appropriately normed test.s. ${ }^{20}$ Different levels and examples of acquired impairment of activities of daily life (ADL) when diagnosing HAND is described by the authors. ${ }^{20}$ Before a diagnose of ANI, MND or HAD is given, several co morbid conditions has to be excluded in the patient. Such co morbid conditions include CNS opportunistic infections, medications with CNS effects, cerebral tumours, metabolic disturbances, or other developmental or acquired conditions unrelated to HIV disease. ${ }^{20}$

A second level of $\mathrm{co}$ morbid condition is a contributing condition, i.e. the condition has had some substantive contribution to the neuropsychological impairment, for example a previous traumatic brain injury or a developmental disorder, but the effect of HIV is also considered to be significant. If a patient with suspected HAD also meet the criteria for a severe episode of major depression with significant functional limitations or psychotic features, or substance abuse, the diagnosis of HAD should be deferred to a subsequent examination performed at a time when the major depression has remitted or at least 1 month has elapsed since cessation of substance abuse. ${ }^{20}$ In the research nosology for HAND from 2007, it is further commented that the consensus was that even when major depression and HAD occur together, there is little evidence that pseudodementia exists and the cognitive deficits do not generally improve with treatment of depression. ${ }^{20}$

In many resource-limited settings standardized neuropsychological examination procedures and other diagnostics tools, e.g computed tomography (CT) or magnetic resonance imaging (MRI) are not yet available. In particular, the neuropsychological tests and functional assessments may not have been validated in the language of many countries, or normative standards may be lacking. ${ }^{20}$ In these situations, the diagnostic guidelines for HAND from 2007 may be followed in principle, using clinical judgment and assessments aimed at establishing the same criteria. ${ }^{20}$

If neuropsychological testing is not available, presence of cognitive impairment involving two or more ability domains may be detected by standardized mental status examinations, using appropriate demographic normative cut-offs if available. ${ }^{20}$ The HIV Dementia Scale (HDS) is a bedside screening tool to identify HAD and to monitor therapeutic effects. ${ }^{22,33,34}$ The HDS is comprised of four tasks that evaluate memory, psychomotor speed, construction ability and executive functions, and is specially designed for a condition with subcortical dementia. The HDS has a sensitivity of $80 \%$ and a specificity of $91 \% .{ }^{33}$ It appears to be widely used because of its ability to distinguish patients with frank dementia from those who are cognitively normal. For the increasing number of patients with mild dementia and MND following the introduction of HAART, the HDS, as a screen, is not as accurate in detecting $\mathrm{HAD}$ as a more thorough neuropsychological examination. ${ }^{35}$ The International HIV Dementia Scale (IHDS) is another, new screening test. ${ }^{32}$ The anti-saccadic error subtest of the HDS has proven difficult for non-neurologists to administer, and the HDS also includes subtests (alphabet writing and cube-copying tests), which may be difficult for individuals with a non-Western educational background. ${ }^{32}$ The IHDS eliminates the antisaccades subtest and replaces the timed written alphabet and cube copy time subtests with tests of motor speed and psychomotor speed which can easily be performed across different cultures. The IHDS consists of three subtests: finger tapping, timed alternating hand sequence, and recall of four items at two minutes. ${ }^{32}$ In a study comparing patients in the U.S. and Uganda, its sensitivity was 80\% and specificity 55-57\%, making it useful as a screening instrument, both in the industrialized world and the developing world. ${ }^{32}$ As with the HDS, full neuropsychological testing should be performed to confirm a diagnosis of HAD. ${ }^{32}$ The Mini-Mental State Examination ${ }^{20}$ is an additional test that might be used to screen for cognitive impairment. Example of cognitive domains screened for in the tests presented above is given by Anitinori and colleagues. ${ }^{20}$

$\mathrm{HAD}$ has been estimated to occur in $15-30 \% \%^{3,11}$, of untreated HIV individuals and in approximately half of paediatric patients. ${ }^{3}$ AIDS patients in the late stages might have a more than $50 \%$ prevalence of $\mathrm{HAD}$, and autopsy studies have revealed that up to $90 \%$ of patients with AIDS may have pathological indicators of HIVE. ${ }^{5} \mathrm{HAD}$ and myelopathy generally do not develop until advanced HIV infection. HAD may, however, be the only presenting manifestation of AIDS ${ }^{5,36}$, but is rare among otherwise healthy HIV-infected persons. ${ }^{11}$ Milder forms of cognitive impairment, MCMD, has been reported to exist in at least 30\% of symptomatic HIV-positive adults. 11,37 The combined measurement of plasma HIV RNA and CD4 lymphocytes predicts the prognosis of HIV/AIDS ${ }^{11}$, and CSF levels of HIV RNA correlate with the severity of neurological deficits, at least before the era of HAART. ${ }^{11}$

The WHO Neuropsychiatric AIDS study examined the prevalence of HIV-associated neurological and cognitive abnormalities in five geographical regions worldwide 19901991, using a neuropsychological test battery, a neurological examination, a structured interview for the diagnosis of $\mathrm{HAD}$ and a functional assessment. ${ }^{38}$ The prevalence of $\mathrm{HAD}$ for symptomatic HIV-positive patients was 4.4-6.9\% in both Kenya and Democratic Republic of Congo, which was similar to the prevalence in Germany and Brazil. The prevalence of HAD in Africa was quite low in this study, possibly because the HIV epidemic was still in its early stages in this region in 1990 1991.39 In other studies from Africa, the frequencies of HAD in Northern Tanzania (1989) was seen in 54\% of cases ${ }^{40}$, in $8.7 \%$ of cases in Kinshasa, Democratic Republic of Congo (1992) and in 16\% of cases in a rural Ugandan hospital (2002). ${ }^{39}$ However, formal neuropsychological testing was not performed as part of these studies, and differences in the diagnostic criteria for dementia could also account for the variance in the prevalence of HAD in these case series. ${ }^{39}$ Wong and colleague ${ }^{42}$ made detailed sociodemographic, medical history, neurological, neuropsychological, and functional assessments on 78 people with HIV (mean CD4 cell count 219 cells $/ \mathrm{mm}^{3}$ ) and 100 people who were HIV negative in Kampala, Uganda. HAD was present in $31 \%$ of all patients with HIV and an additional $47 \%$ of the patients met the criteria for mild cognitive impairment on neuropsychological testing. 
Important risk factors for a diagnosis of HAD included subjective memory complaints, low education, low performance on the IHDS, advanced age and low CD4 cell count. Each additional 10 years of age conferred a greater than twofold risk of HAD. ${ }^{42}$ The study included HIV-positive individuals who had more advanced HIV infection than those in the WHO study. ${ }^{39}$ Salawu and colleagues ${ }^{43}$ studied the cognitive function in 60 asymptomatic, treatment-naïve HIVpositive Nigerians. These individuals differed significantly from individually matched, HIV-negative control subjects, and 56.6\% showed cognitive impairment (at least one test -2 SD), compared to $13.3 \%$ in the control group. The CD4 cell count of the HIV-positive subjects had no significant correlation with the cognitive test scores, suggesting that cognitive changes during asymptomatic and early symptomatic HIV infection were not the result of immunosuppression in this group of patients. ${ }^{43}$

The different frequency of $\mathrm{HAD}$ in different regions raise the possibility that HIV subtypes, or clades, might have different biological properties with respect to their capacity to cause HIV-associated cognitive impairment. ${ }^{39}$ In North America and Europe, clade B is the predominant HIV-1 subtype, while in Africa several different subtypes with different distribution are known. ${ }^{39}$ Clade $\mathrm{C}$ is the predominant HIV subtype in Ethiopia and Southern Africa, while D and A subtypes predominate in Uganda. ${ }^{39}$ In a recent study from Ethiopia, HIV-associated cognitive impairment was evaluated in 73 HIV-positive individuals (CD4 cell count $260 \mathrm{cells} / \mathrm{mm}^{3}$ ) and 87 HIV-negative individuals. ${ }^{44}$ The HIV-positive subjects had slower performance than the HIV-negative individuals in the finger-tapping test, but there were no differences between the performance of HIV-positive and HIV-negative individuals in any other neuropsychological test, or in the IHDS total score. However, Joska and colleagues reports that HAND was present in $23.5 \%$ in a sample of 536 HIV-patients (of which half were on antiretroviral medication) from South Africa. ${ }^{45}$ It has recently been shown in a mouse model, that HIV-l clade B have greater impact on the induction of neuropathogenesis than clade $\mathrm{C}^{46}$ If this has clinical significance in humans remains to be determined. The occurrence of neurocognitive impairment in HIV positive individuals during the era of HAART is given at the end of this review.

\section{Psychiatric manifestations of HIV disease}

The interplay between biologic, psychologic and social circumstances associated with HIV disease can be complicated. Careful diagnosis and treatment of psychiatric disorder in HIV positive patients are important as psychiatric manifestations can have serious effects if not identified. The occurrence of cognitive impairment in case of HAND might complicate a diagnosis of depression. Some psychiatric symptoms might also be directly related to $\mathrm{HAD}$, as for example secondary mania or psychosis.

Knowledge of the metabolic pathways of psychopharmacologic agents as well as antiretrovirals is important because of potential adverse drug-drug interactions. Furthermore, patients infected with HIV have an increased sensitivity to side effects of psychotropics. Having this in mind, strategies similar to those that apply for the treatment of psychiatric disorders in the general population could be followed. ${ }^{47}$ However, controlled trials with HIVpositive individuals of several psychotropic agents are needed in the future. Given that psychiatric illness is present in almost half of HIV-positive individuals and that, of these patients, around 50\% do not receive psychotropic medication ${ }^{48}$, knowledge of the spectrum of mental disorders among HIV patients is vitally important.

\section{Depression}

Depressive spectrum disorders seem to be the most common psychiatric manifestations of HIV disease. ${ }^{47}$ Major depressive disorder (MDD) is more prevalent among HIV-infected individuals than in the general population, with estimated prevalence rates varying widely from $2 \%$ to $30 \%$, or even up to 50\% of the HIV-positive patients. ${ }^{47-52}$ Patients with HIV are 2-7 times more likely to meet diagnostic criteria for current MDD than individuals in the general population.50 The variable prevalence rates of MDD reported are probably explained by variations in study population and design, with differences in age, sex, education, ethnicity and stages of HIV/AIDS. For example, lower rates of MDD are found among patients who had not progressed to AIDS. ${ }^{50}$ Furthermore, different degrees of HIV cognitive impairment influence the patient's symptoms, which may be difficult to elucidate in the individual patient. Earlier prevalence studies have mainly focused on HIVseropositive men. Estimates of depression among HIV-positive women range from $1.9 \%$ to $35 \%$ in clinical samples and from $30 \%$ to $60 \%$ in community samples. ${ }^{47}$ In a study of 93 HIVpositive women and 62 HIV-negative control women, MDD was significantly higher among the HIV-positive women (19.4\%) than among the negative controls (4.8\%). ${ }^{53}$

MDD in HIV infected patients may be a primary consequence of CNS effects of HIV, a reaction to the stigmatization and emotional consequences of the diagnosis and coping with a serious medical illness, or a combination of these factors, thus constituting a heterogeneous group of affective disorder ${ }^{50}$ with neurovegetative confounding factors. ${ }^{47}$ Depression in individuals with HIV on HAART and without symptoms of HAD does not seem to be a clinically distinct subtype. ${ }^{52}$ Depression in HIV-positive patients might, however, influence the immune response. ${ }^{54}$ For example, MDD has been shown to alter the function of killer lymphocytes in HIVinfected women, resulting in increased levels of CD8 lymphocytes and HIV 55 , and depression might lead to a progression of HIV disease and an increase in mortality rate. $47,48,55,56$ Depression might be unrecognized and untreated in many patients with HIV infection. Several of the cognitive symptoms of HAD may be difficult to differentiate from depression ${ }^{5}$, and they may both precipitate similar symptoms as for example anorexia, insomnia, fatigue and pain, and they may both affect the serotonergic system. ${ }^{47,57}$ The presence of anhedonia coupled with diminished mood in the morning indicate the presence of MDD. ${ }^{47}$ Depression may be the initial presentation of HAD, and may be associated with the progression of cognitive impairment. ${ }^{57}$ In addition, patients who demonstrate depression and cognitive impairment together may not respond well to treatment. ${ }^{58}$ Instruments to assess depression that allow one to separate out items describing somatic symptoms from those concerning depressed mood should be used, as somatic symptoms associated with depression may also be caused by HIV infection. ${ }^{20}$ Some neuropsychological test may help in differentiating patients with HIV cognitive impairment with and 
without depression. ${ }^{59}$ Depression does not seem to influence basal ganglia-mediated psychomotor speed, and such psychomotor evaluation of CNS function or dysfunction in HIVpositive patients might be used without having to take depression into account. ${ }^{60}$ Suicidality may be cause for psychiatric referral in those subjects who have been informed about a diagnosis of HIV/AIDS. ${ }^{61}$ In general, MDD in HIV patients lead to a decrease in adherence to HAART. ${ }^{47,48}$ However, appropriate psychiatric intervention may increase adherence to HAART, improve quality of life and decrease mortality. Therefore, detecting and treating MDD in HIV positive individuals is even more important. ${ }^{48}$

Selective serotonin reuptake inhibitors (SSRIs) are effective in treating depression in HIV-infected patients. A more benign side effect profile with SSRIs has limited the use of tricyclic antidepressants (TCAs) to those HIV patients who do not respond to more modern antidepressants. ${ }^{47,62}$ There are a number of limitations of the available literature that has to be considered. In particular, the majority of controlled studies were conducted before the advent of HAART. ${ }^{62}$ Safety concerns have been raised concerning potential interactions between SSRIs and antiretroviral drugs. Protease inhibitors and non-nucleoside analogue reverse transcriptase inhibitors (NNRTIs) may affect the activity of cytochrome P450 isoenzymes, interacting with drugs metabolized by the same pathway including antidepressants, neuroleptics and anticonvulsants. ${ }^{63}$ A serotonergic syndrome in four patients receiving fluoxetine in combination with antiretrovirals that included ritonavir, efavirenz or sanquinavir ha been reported. ${ }^{64}$ To avoid such complications, a reduction of the initial SSRI dose, slow titration, and close monitoring for toxic reactions are recommended. ${ }^{62}$ Known interactions between antidepressants and antiretrovirals should always be considered before the medication is started.

The serotonin and noradrenaline reuptake inhibitors (SNRI) represent an attractive alternative when treating depression in HIV-infected patients. Venlafaxine and duloxetine have been tried to a certain extent, but more studies are needed on the effectiveness and safety of these SNRIs when treating patients with HIV. These agents are also effective to treat chronic pain, which often is under treated in HIV individuals. ${ }^{62}$ Mirtazapine has been studied in a 12-week open-label study in 12 HIVpositive patients diagnosed with major depression. Mirtazapine was well tolerated and effective, and the participants reported a significant reduction of heaviness, loss of energy and fatigability ${ }^{65}$, but larger studies should be accomplished. Also buproprion and reboxetine has been studied in small, open trials with HIV-positive patients, and suggests efficacy similar to that observed in the controlled of SSRIs and TCA.s. Controlled trials with HIV-positive individuals of these newer agents are needed. ${ }^{47}$

\section{Anxiety syndromes, adjustment disorder and posttraumatic stress disorder}

Anxiety syndromes and symptoms are common among HIVpositive individuals, and often related to HIV symptoms, fatigue and physical limitations. ${ }^{50,66}$ The presence of persistent focus on death and mortality issues has been found to be common among HIV-positive patients in the symptomatic stage of the disease. ${ }^{50}$ The prevalence of generalized anxiety disorder (GAD) is increased in HIV-positive patients compared to HIV- negative individuals. ${ }^{50}$ Adjustment disorder, arising in response to difficult life events, is also common among HIV patients. ${ }^{48}$ Adjustment disorder was reported in around onethird of the patients in one study, and was prevalent at both asymptomatic and symptomatic stages of the HIV infection. ${ }^{67}$

Posttraumatic stress disorder (PTSD) is another potential consequence of receiving a HIV/AIDS diagnosis. ${ }^{61}$ In one study, one-third of 61 HIV-positive patients met the criteria for a syndrome of PTSD in response to HIV diagnosis. ${ }^{68}$ PTSD in these patients was significantly associated with a pre-HIV history of PTSD from other causes, and with major depression arising after HIV infection. In a study from South Africa, the prevalence of PTSD was 30.6\% in a sample of patients attending HIV clinics, reflecting the high rates of trauma and violence in the community according to the authors. ${ }^{45}$ PTSD was here significantly associated with HAND and the effect was dependent on the educational level. ${ }^{45}$

Controlled studies assessing the efficacy and safety of anxiolytic medication in HIV-infected persons are lacking, including studies evaluating the efficacy of antidepressants for treating anxiety disorders in HIV-positive patients. ${ }^{62}$ In USA, benzodiazepines account for over $60 \%$ of all anxiolytics prescribed. Interactions between benzodiazepines and antiretrovirals have been reported. For example, due to its inhibitory effects on the CYP3 isoenzyme, low doses of ritonavir can significantly impair the clearance of alprazolam. ${ }^{62}$

\section{Mania}

Mania is seen in heightened rates among individuals with HIV/AIDS, especially with the progression of HIV infection. Hypomanic or manic behaviour, including increased sexual activity and drug use, is an additional risk factor for contracting and transmitting HIV. ${ }^{50}$ Mania in a patient with HIV/AIDS may occur as part of a coexisting bipolar disorder, or it may be secondary to the effects of HIV infection on the CNS, treatments for HIV infection, or HIV-related secondary infections of the brain. ${ }^{69}$ Of these, HIV neurotoxicity has been postulated to be the most important factor in the pathogenesis of secondary mania among HIV positive individuals. ${ }^{69-73}$ In one study ${ }^{72}$, patients with secondary mania (without family or personal history of mood disorder) and HIV presented later in the course of HIV infection, and were more likely to have developed AIDS, to have a low CD4 count and to have a higher prevalence of co morbid dementia or cognitive slowing compared to HIV-positive patients with primary mania, suggesting that secondary mania may be a direct effect of HIV on the CNS. The authors reported that the 17-month prevalence of mania in the studied population of HIV-positive patients was $1.4 \%$, and the rate in the patients with AIDS was 8 $\% .{ }^{72}$ Patients with secondary mania had more symptoms and were more likely to show irritability, and less likely to display increased talkativeness. ${ }^{73}$ In another study, the prevalence of secondary mania over a 29 months study was $1.2 \%$ for HIVpositive patients, and $4.3 \%$ for those with AIDS. ${ }^{71}$ The patients in these studies were mostly males. Evidence for an etiological association between HIV disease and secondary mania was indicated in a study of HIV-positive patients with and without mania that demonstrated a protective effect from zidovudine, an antiretroviral agent penetrating the CNS. ${ }^{74}$ However, conclusions are tentative due to the small sample sizes in these studies. Secondary mania has been reported to occur 
with various disorders or processes that disrupts brain structure or physiology. ${ }^{75}$

In a larger study from Uganda, 64 HIV-negative patients with primary mania were compared to 61 patients with HIVrelated secondary mania. ${ }^{69}$ Compared to the patients with primary mania, the patients with secondary mania had more manic symptoms; they were more irritable, more aggressive and disruptive, more talkative, more likely to have a decreased need for sleep, and had higher rates of psychotic symptoms such as paranoid delusions (92\% compared to 80\%), visual hallucinations (93\% compared to 16\%) and auditory hallucinations (67\% compared to 16\%). Furthermore, they were more cognitively impaired (84\% compared to $45 \%$ in primary mania), less educated, and more likely to be female. Among the patients with secondary mania, only half had been aware of their HIV status prior to their psychiatric hospitalization. In several of the patients, mania was the first revealing symptom of HIV infection. The majority of the HIVpositive patients (90\%) did not have HIV-related illnesses other than the mania, lacking for example HIV wasting syndrome, Kaposi's sarcoma or opportunistic infections as Pneumocystis carinii or cryptococcal meningitis. ${ }^{69}$ According to the WHO clinical system for HIV/AIDS76 48\% of the HIV positive patients were in stage 1 or 2 , and $52 \%$ in stage 3 to $4 .{ }^{69}$ The authors suggest that secondary mania may be used as an indicator to initiate HAART

Mood stabilizers as lithium and valproic acid (VPA) has been evaluated in pilot studies as adjunct therapy to ART (see below). ${ }^{77,78}$ They seem to be well tolerated and they might even improve neuropsychological performance. ${ }^{77,78}$ Consequently, they might also be used as mood stabilizers for treating bipolar symptoms in HIV-positive patients, but larger studies should be performed. For example, in one other study, a small case series of 10 HIV-positive patients, lithium was not well tolerated. ${ }^{79}$ Valproic acid should probably be used in conjunction with antiretroviral therapy, as VPA might increase HIV replication. ${ }^{62}$ Lamotrigine was tested in a randomized, placebo-controlled study and was effective in treating neuropathic pain in 92 HIV-positive patients receiving antiretroviral therapy. ${ }^{80}$ However, the antiretroviral drugs lopinavir and ritonavir decrease lamotrigine plasma levels. ${ }^{81}$ Carbamazepine is an inducer of CYP3A enzymes and may increase the metabolism of the antiretroviral drugs indinavir and delavirdine. ${ }^{47}$ On the other hand, ritonavir may raise the serum levels of carbamazepine. ${ }^{82}$ Further studies on the use of mood stabilizers in HIV-infected individuals are clearly needed, including those considering drug interactions. ${ }^{62}$

\section{Psychosis}

Psychotic disorders can be classified into primary (e.g schizophrenia, schizoaffective disorder) or secondary (e.g. psychosis caused by a medical condition such as HIV infection) disorders in the DSM-IV nosology. Thus, psychotic symptoms may be seen in HIV infected individuals due to several factors. Psychotic disorders may precede HIV infection. Patients with schizophrenia are at increased risk for co morbid HIV infection because of an elevated likelihood of poor impulse control, impaired judgement, substance abuse and high-risk sexual behaviour. ${ }^{83}$ Although being sexually active tends to be less common among patients with schizophrenia, patients with schizophrenia who are sexually active are more likely to be engaged in high-risk behaviour. ${ }^{50,84-86}$ HIV disease tends to lead to greater morbidity and mortality in patients with schizophrenia than in the general public due to several reasons, such as difficulty complying with medical care and trouble explaining symptoms to medical personnel. ${ }^{86}$

It has been shown that the HIV infection per se may be associated with psychotic symptoms. Studies have showed that new-onset psychosis in HIV positive patients occurred in $0.2 \%$ to $15 \%$ of the patients, with the highest incidence reported among patients in later stages of HIV disease and with $\mathrm{HAD}^{50,86,87}$, suggesting that psychosis may be a direct effect of HIV infection on the CNS. 15\% of 46 patients with HAD reported psychotic symptoms in one study ${ }^{88}$, and these data were supported by a case study, in which patients with psychosis showed greater neurocognitive impairment than HIV-positive patients without psychosis. ${ }^{89}$ The presenting symptoms are highly variable, but persecutory, grandiose, and somatic delusions are the most common symptoms, followed by auditory and visual hallucinations and affective disturbances. ${ }^{83}$ In a case study of 20 HIV-positive men with new-onset psychosis, all 20 presented with delusions, 12 with auditory and 9 with visual hallucinations, while mood symptoms occurred in 13 patients. ${ }^{89}$ Compared to schizophrenia, bizarre or complex delusions are less common in new-onset psychosis in HIV-infected individuals, and visual hallucinations and remission of psychosis are commonly found. ${ }^{83}$ Furthermore, as presented above, psychotic symptoms are commonly found among patients with secondary mania due to HIV disease. ${ }^{69}$

A number of hypotheses have been proposed to explain the pathogenesis of new-onset psychosis in HIV disease: subcortical neurodegeneration caused by HIV itself or in the presence of other viral infections; psychosis secondary to HIVE; brain damage from some other opportunistic infection, or an underlying dementia. ${ }^{83}$ The following factors have been reported to be associated with the development of psychosis in HIV infected patients: untreated HIV infection, cognitive impairment, dementia, and a history of psychiatric disease or substance abuse.

The use of HAART in HIV-infected patients may be expected to reduce the risk of new-onset psychosis secondary to HAD. HIV-positive patients with neuro-AIDS are more sensitive to side effects of antipsychotic agents, especially extrapyramidal side-effects (EPS), due to a loss of dopaminergic neurons. ${ }^{23}$ Modern antipsychotics (risperidone, quetiapine, sertindole, olanzapine, ziprasidone, aripiprazole) seem to represent an advance over first generation antipsychotic agents when treating psychotic symptoms in these patients due to a reduced risk of EPS. ${ }^{83}$ Clozapine should be used cautiously due to the risk of bone marrow suppression with agranulocytosis or lowered leukocyte levels. ${ }^{83}$ Lower starting doses, slower titration and close monitoring of side effects are recommended when treating HIV-infected patients with antipsychotic medication. ${ }^{62,83}$ Drugdrug interaction has been reported between risperidone and the antiretroviral ritonavir, resulting in high risperidone serum levels and consequent EPSs ${ }^{90}$, or neuroleptic malignant syndrome ${ }^{91}$ However, there is a lack of controlled studies of the efficacy or side effects of antipsychotic drugs in HIV positive persons, as well as studies of potential interactions with antiretroviral medications. ${ }^{62}$ Clearly, such trials are 
needed. The antiretroviral efavirenz may give rise to psychotic side effects (see below).

\section{Substance use disorders}

There is a high prevalence of substance abuse among HIV infected individuals ${ }^{50,92}$; studies have shown lifetime rates as high as 40-50\%; in one study even as high as 74\%. ${ }^{48}$ Researchers evaluating the relationship between substance abuse and HIV outcomes have primarily focused on injection drug users, but also alcohol, marijuana, amphetamines, cocaine and hallucinogens are frequently associated with HIV. $^{21,92}$ In a recent study from South Africa, 35.8\% of 536 patients attending HIV clinics reported alcohol abuse according to a screening test. ${ }^{45}$ Furthermore, drug and alcohol use disorders are frequently co morbid also with other psychiatric diseases as depression, anxiety and severe mental illness. The combination of severe mental illness and substance use creates raised HIV risk, for example by increased sexual and needle-use risk-taking. HIV positive drug abusers are reported to have higher rates of both $\mathrm{HAD}$ and HIVE compared to HIV infected non-drug abusers. ${ }^{4,6}$ Up to $30 \%$ of injection drug users are HIV positive, and they seem to have more rapid neurologic progression. ${ }^{21} \mathrm{HIV}$ related brain pathology thus seems to be worse in drug abusers compared to that seen in drug free patients. ${ }^{4}$ At present, there are no laboratory or clinical based methods to distinguish HIV mediated effects from drug abuse mediated effects on the brain. ${ }^{21}$ It has been shown that intravenous drug users with HAD do less well on HAART than non-drug users ${ }^{93}$, and there might be greater difficulties in achieving compliance in drug users on antiretroviral therapy. ${ }^{4}$ At least 1 month should have elapsed since cessation of substance abuse before a diagnosis of $\mathrm{HAD}$ is made. ${ }^{20}$

\section{Antiretroviral therapy: the era of HAART}

The clinical manifestation of AIDS and HAD carries a poor prognosis for the affected patient. The introduction of highly active antiretroviral therapy (HAART) in 1996-1997 had a dramatic effect on HIV disease and increased the life expectancy for HIV-infected patients, and resulted in a 50\% decline in AIDS death rate. ${ }^{11}$ Maternal-infant transmission rates have also decreased. ${ }^{11}$ The improved immune system protects against opportunistic infections and the incidence of such infections has fallen. ${ }^{6}$ Since the introduction of HAART, HIV infection in western countries has been transformed from an almost uniformly fatal condition to a chronic, manageable disease, even though some patients fail to achieve efficient viral suppression after receiving HAART due to drug resistance or lack of adherence.

HAART is now usually given as a combination of three or four different antiretroviral drugs from at least two different drug classes. There are over 20 different antiretrovirals approved, distributed in four different classes of antiretroviral drugs: nucleoside/nucleotide analogue reverse transcriptase inhibitors (NRTIs; e.g. abacavir, emtricitabine, lamivudine, stavudine, tenofovir, zidovudine), non-nucleoside analogue reverse transcriptase inhibitors (NNRTIs; e.g. efavirenz, nevirapine), protease inhibitors (e.g. lopinavir, ritonavir) and fusion inhibitors (enfuvirtide). ${ }^{94}$ The WHO has developed guidelines for the use of HAART in resource-limited settings. ${ }^{95,96}$
The WHO recommends that HIV-infected adults and adolescents should start ART therapy when there is WHO stage IV HIV disease, irrespective of the CD4 cell count, and in WHO stage III with consideration of using CD4 cell counts $<350$ cells $/ \mathrm{mm}^{3}$ to assist decision-making. For those with WHO stage I or II HIV disease, a CD4 cell count of $<200$ cells $/ \mathrm{mm}^{3}$ or a total lymphocyte count of $\leq 1200$ cells $/ \mathrm{mm}^{3}$ should trigger initiation of ART. The preferred regimens for initiating HAART under these circumstances are the combination of two nucleosides and one of the non-nucleoside drugs: stavudine or zidovudine (alternative: tenofovir or abacavir) plus lamivudine or emtricitabine, plus nevirapine or efavirenz. ${ }^{96}$ Triple NRTI approach can be considered as an alternative for first-line regimens in situations where NNRTI options provide additional complications. ${ }^{96}$ Computer programs for predicting response to combination antiretroviral therapy, given the viral genotype and further information, have lately been developed. ${ }^{97}$ Since the process of reverse transcription lacks a proofreading mechanism, mutations leading to drug resistance are generated frequently. ${ }^{97}$

Efavirenz has well documented acute CNS side effects, and have been reported in up to $50 \%$ of the patients. Such side effects include dizziness, light-headedness, somnolence, insomnia, unusual dreams, amnesia, agitation, derealisation, depersonalization, hallucinations and euphoria, and typically begin after the first dose and usually resolve within 2-4 weeks of therapy or somewhat later. ${ }^{94,98}$ In certain patients, some symptoms may not completely resolve and persisting CNS side effects have been reported. ${ }^{98}$ Several other complications can occur during antiretroviral medication, for example metabolic and morphological changes such as lactic acidosis, lipoatrophy, fat accumulation and dyslipidaemia. ${ }^{96}$ The immune reconstitution inflammatory syndrome (IRIS) is a spectrum of clinical signs and symptoms resulting from the restored ability to amount an inflammatory response associated with immune recovery. ${ }^{99}$ The incidence of IRIS is estimated to be $10 \%$ among all patients initiating antiretroviral therapy. ${ }^{96}$

In the era of HAART, incidence rates of HAD have dropped by 15 to $50 \%{ }^{11,21,100}$, to as low as $10.5 \% 100$ or even lower. ${ }^{101}$ HAART can improve cognitive performance in some patients with HIV-associated cognitive impairment. ${ }^{102,103}$ It is not clear whether HAART protects the brain by restraining progress of the initial HIV infection in the CNS, or by controlling replication in the periphery and reducing the chance of later viral reinfection of the brain. Probably HAART acts in both ways. ${ }^{4}$

However, HAART has failed to provide complete protection from $\mathrm{HAD}$ or reversal of the disease in many cases ${ }^{9}$, and the frequency of the milder form of HIV-associated cognitive impairment, minor cognitive motor disorder (MCMD) has not been reduced. ${ }^{11,37}$ Furthermore, the frequency of HIVE, the pathological manifestation of $\mathrm{HAD}$ and usually characterized only in post-mortem tissue, has remained constant. This suggests that HAART does not eliminate HIV infection in the CNS, although HAART improves the symptoms of HIV infection quite dramatically. ${ }^{3,11} \mathrm{HIV}$ is believed to persist in sanctuary sites within the body even in optimally treated patients, and HAART is not a cure for HIV. The brain is believed to be one of the key sanctuary sites with limited immune surveillance and persistent HIV replication in microglial cells and perivascular macrophages. ${ }^{6,11}$ It has further been suggested, that the poor penetration of antiretroviral drugs across the blood-brain 
barrier into the CNS could allow the potential for viral sequestration in the brain and potentially cause continuing neurological decline. ${ }^{104}$ These viral reservoirs may also increase the risk for drug resistance and reseed the systemic compartment. ${ }^{11,105}$ Several studies show a significant correlation between the number of neuroactive drugs in the antiretroviral regimen and CSF viral replication ${ }^{106-108}$, though other studies have not found such a correlation on CSF replication or clinical statu. ${ }^{36,101,109}$ Even though some controversy remains, it seems reasonable that neurocognitive outcomes of HAART may be enhanced by selecting HAART regimens that optimize penetration across the BBB. However, definitive conclusions concerning the importance of CSF penetration of antiretroviral drugs will probably require longterm follow-up data from clinical trials. ${ }^{101}$ When faced with a patient on HAART but in whom cognitive impairment is developing, and whose plasma HIV level is well controlled, the CSF HIV level should be measured. If HIV RNA is detectable in the CSF, it might be necessary to change the HAART regimen. ${ }^{57}$

Studies have revealed that the major site of inflammation in HIVE seems to have shifted from a subcortical pattern including the basal ganglia seen before the HAART era, to the hippocampus and surrounding entorhinal and temporal cortex during HAART treatment. ${ }^{6} \mathrm{HAD}$ in the HAART era might thus present with a mixed phenotype, with both cortical and subcortical features, and is often milder, having a variable progression pattern, and appears at a higher CD4 cell count. ${ }^{57}$ The impact on cortical brain regions in the era of HAART alters the clinical expression of cognitive impairment in HIV-positive patients, and such changes have been identified in neuroimaging and in neuropsychological testing profiles. ${ }^{110,111}$ Since the introduction of HAART a substantial proportion of HIV-infected individuals (<20\%) have bidirectional changes in neurocognitive symptomatology, fluctuating from normal to abnormal and vice versa, at different levels of severity.11,20 This fluctuation may represent a relapsing pattern of cognitive impairment, reflecting a fluctuation of inflammatory processes due to secondary factors as degree of viral suppression, treatment regimens, medication adherence and drug toxicities. ${ }^{110}$ Future research should try to analyze the causes of this fluctuation, for example if it reflects biological changes induced by responses (or failures) of antiretroviral therapy, and the effects on everyday function, treatment outcomes and patient survival. ${ }^{20,110}$ Some individuals with HIV neurocognitive impairment fail to respond to HAART. Such events may correspond to an irreversible stage of pathology with prominent neuronal loss. ${ }^{11}$ Determinants of treatment response are still unclear, but higher initial levels of CNS inflammation may correlate with reversible neurological deficits. ${ }^{11}$

In the US, HAART has been associated with improvement in neurocognitive performance among HIV-positive individuals with a CD 4 count of $>200$ cells $/ \mathrm{mm}^{3}$ as well as CD4 count of $\leq 200 \mathrm{cell} s / \mathrm{mm}^{3}$. 102 This has to be further evaluated on subSaharan populations. ${ }^{112}$ However, WHO guidelines states that the presence of HIV clinical disease stage IV, for example HIV encephalopathy, should result in initiation of HAART, independent of CD4 count. The recognition of HIV-associated asymptomatic neurocognitive impairment (ANI) might also promote the initiation of antiretroviral therapy, independent of CD4 count or plasma HIV RNA levels, but this requires further study. ${ }^{20}$ Sacktor and colleagues studied the effect of HAART on cognitive impairment in a sub-Saharan cohort (23 HIV-positive individuals from Kampala, Uganda). ${ }^{112}$ There was a significant improvement in the Memorial Sloan Kettering HIV dementia stage and in tests of verbal memory, psychomotor speed and executive functioning after 6 months of HAART. The mean CD4 cell count improved from $71 \mathrm{cell} / \mathrm{s} / \mathrm{mm}^{3}$ at baseline to 161 cells $/ \mathrm{mm}^{3}$ at 3 months and 222 cells $/ \mathrm{mm}^{3}$ at 6 month. ${ }^{112}$ The results from this study suggest that HAART should be provided for patients with HIV-associated cognitive impairment, also in resource-limited areas in sub-Saharan Africa. ${ }^{112}$

HIV infection in older patients (aged $>50$ years) is becoming increasingly common as HIV-positive individuals live longer because of HAART treatment. The long-term consequences of chronic infection and extended exposure to HAART with respect to the brain are not known. Additive effects of for example drug abuse or co-infection with hepatitis C virus should also be considered. ${ }^{21}$ Several studies have identified an increased rate of HAD among older patients, but whether there is an additive or synergistic relationship between aging and HIV on neuropsychological performance is not clear. ${ }^{110}$ In addition, it is not known if HIV infection increases the risk for other age-related neurodegenerative disorders, perhaps by decreasing the age of onset and lower the threshold for the clinical presentation. ${ }^{110}$ In another study by Sacktor and colleagues ${ }^{113}$, the neuropsychological test performance between old and young HIV-positive cases were compared in patients with or without cognitive impairment, and in patients with dementia. Increased age was associated with lower performance in tests of executive functioning, memory and motor performance in patients with or without cognitive impairment, whereas older HIV-positive individuals with dementia may have greater decline in executive functioning compared to younger HIV-positive individuals with dementia. These differences could be a result of advance age itself or age-associated co morbidities such as coexisting neurodegenerative or cerebrovascular disease. ${ }^{113}$

With HAART, dramatic reductions in plasma HIV levels can be seen within weeks, while immunological response occurs over a few months, and can be dramatic with normalization of CD4 counts. ${ }^{11}$ HAART also causes a reduction of HIV RNA levels in the CNS. ${ }^{114,115}$ Before HAART, traditional biomarkers such as CD4 level, plasma viral load, CSF viral load, and immune activation, e.g. monocyte chemoattractant protein-1 (MCP-1) and beta 2 -microglobulin, were helpful in the diagnosis of HAD. ${ }^{57}$ However, during the era of HAART these biomarkers are less likely to be associated with dementia in treated HIV patients. ${ }^{11,104,116,117}$ For example, undetectable CSF HIV RNA do not indicate inactive HAD in HAART-treated patients. ${ }^{117}$ More sensitive assays are needed to reliable detect levels of HIV replication and active HIVE in the CNS. Bandaru and colleagues examined potential CSF biomarkers in patients with HIV, the majority on HAART, based on changes in cognitive status over a 1-year period. ${ }^{116}$ They found that increased levels of vitamin E and triglyceride C52 predicted the onset or worsening of dementia, and that elevated levels of sphingomyelin was associated with inactive dementia. Elevated levels of ceramide and the accumulation of 4hydroxynonenals were associated with active dementia. These findings indicate an initial up-regulation of the antioxidant defence early in the pathogenesis in $\mathrm{HAD}$. The failure of this 
defence mechanism leads to an accumulation of sphingomyelin. The breakdown of sphingomyelin to ceramide and the accumulation of reactive aldehydes are associated with a decline in cognitive function. ${ }^{116}$ Thus, a combination of markers of oxidative stress and neuronal injury might be useful in the future for following patients with HAD. However, these tests are currently available only in research laboratories.

Recent studies have shown that a marker of neuronal destruction, neurofilament light protein, is elevated in the CSF in patients with HAD. ${ }^{118}$ The possibility that HIV infection in the CNS also might trigger some form of degenerative disease has initiated studies of markers typically associated with Alzheimer's disease, and it has been shown that CSF amyloid beta42 and tau levels correlate with HAD.119

Although the incidence of $\mathrm{HAD}$ has decreased since the introduction of HAART, the prevalence is increasing due to the rising number of infected subjects and increased life expectancy. 6,11,116 The importance of HAD as an AIDS-defining factor has increased ${ }^{9}$, and HIV neurocognitive disorders in the HAART era may occur even in those patients who do not have other evidence of active HIV disease. ${ }^{20}$ However, since the introduction of HAART, the course of HAD appears to be much more variable, and most HAART-treated patients with HAD remain neurologically stable, or may show some partial reversal of neurological impairment, for years after starting with HAART. ${ }^{11}$ The milder form of HIV-associated cognitive impairment, MCMD, or MND, is now more common since the advent of HAART ${ }^{3}$, and survival is considerably longer. ${ }^{20}$ An increased proportion of patients diagnosed with HAD now have a CD4 cell count $>200$ cells $/ \mathrm{mm}^{3}{ }^{100}$, and incomplete neuropsychological improvement following HAART has been described. ${ }^{100}$ Furthermore, the rate of HIVE at autopsy has remained constant or might even be increasing. ${ }^{120}$ Thus, HAD continues to be an important cause of morbidity among HIVpositive patients also in the era of HAART, and significant cognitive impairment may persist within the limits of current treatment approaches. ${ }^{11}$ McArthur and colleagues ${ }^{11}$ suggest that HAD in the era of HAART may have three distinct subtypes: (1) a "subacute progressive" dementia in untreated patients similar to that seen in the pre-HAART era or in patients on HAART with high viral resistance; (2) a "chronic active" dementia in patients on HAART with poor adherence or with low viral resistance, and (3) a "chronic inactive" dementia in patients on HAART with good drug adherence and effective viral suppression. A fourth subtype, "reversible dementia", has been described among patients with good drug adherence and effective viral suppression. ${ }^{57}$ These terms are based on the clinical course of the illness and can of course only be used to classify patients over time. It is very important to be able to identify patients who are at risk for the development of either the subacute progressive or the chronic active form of HAD. ${ }^{57}$

Adjuvant therapies in the treatment of HIV-associated neurocognitive disorders has gained considerable interest, aiming to prevent brain injury or restore neurologic and neuropsychological function by mechanisms other than direct antiviral effects. Even if not as potent as HAART, they may diminish pathogenic events until antiretroviral therapy has reduced the viral burden, and they may provide mechanistic insight into CNS infection and brain injury. ${ }^{57}$ Adjunct benefit have been shown for some psychiatric medications. Two drug classes in particular, glycogen synthase kinase-3 beta (GSK$3 \beta$ ) inhibitors (valproic acid and lithium) and selective serotonin reuptake inhibitors (SSRIs) may be beneficial in this respect. ${ }^{121}$ Valproic acid (VPA), a histone deacetylase inhibitor, can induce activation of latent HIV within resting CD4 cells, possibly leading to an additional depletion of remaining provirus when used in combination with intensive ART therapy. ${ }^{121}$ VPA may also, in conformity with lithium, provide neuroprotection by inhibiting GSK-3 $\beta$, thus protecting neural cells from lipid accumulation and apoptosis. ${ }^{121}$ Schifitto and colleagues conducted a phase II, double blind, placebo controlled pilot study of VPA in HIV infected individuals. VPA was safe and well tolerated, and a small trend toward improvements in neuropsychological performance and brain metabolism was found in the VPA-treated subjects. 78 Lithium has been demonstrated to prevent gp 120-induced HIV neurodegeneration in vitro ${ }^{122}$, an effect probably mediated by inhibition of GSK-3 $\beta$. In a pilot study (single-arm, open-label, 12 weeks duration) low dose oral lithium significantly improved neuropsychological performance within eight cognitive impaired HIV patients already on ART. ${ }^{77}$

SSRIs reduce the expression of CCR5, a chemokine coreceptor, limiting HIV entry into macrophages. ${ }^{121}$ In a recent study, HIV-positive individuals taking SSRIs were less likely to have detectable HIV RNA in CSF compared to non-users. This effect could not be attributed to better mood and adherence to ART. ${ }^{121}$

Memantine, an uncompetitive antagonist of the N-methyl$\mathrm{D}$-aspartate (NMDA) receptor has been used in the treatment of neurodegenerative disorders as Alzheimer's disease. It has recently been tested in a Phase II randomized, double-blind, placebo-controlled, multicenter trial on patients with mild to severe HAD and on stable antiretroviral therapy. Memantine was given for 16 weeks and was safe and tolerated by HIVinfected subjects, but no significant differences in cognitive performance was found, although magnetic resonance spectroscopy data suggested that memantine may ameliorate neuronal metabolism. The authors point out that longer studies are needed to assess the full potential of neuroprotective agents. ${ }^{123}$

Some other agents have also been considered. The CNS stimulant modafinil tested on HIV-positive patients resulted in improved neuropsychological performance in an open-label, 4 weeks study. ${ }^{124}$ The psychostimulants methylphenidate and dextroamphetamine have both been studied in small placebocontrolled trials with some success in patients with HIV, and these observations justify further studies. ${ }^{47}$ The hypothesis that $\mathrm{HAD}$ is associated with oxidative stress and inflammation has led to preliminary studies evaluating the efficacy of selegiline (a dopamine agonist and antioxidant) ${ }^{11,110}$, minocycline (an antibiotic with anti-inflammatory effects) ${ }^{110}$, nimodipine (a calcium channel blocker $)^{47}$ and TNF- $\alpha$ antagonists. ${ }^{11}$ There have been no controlled trials of cholinesterase inhibitors in treating dementia in HIV patients. ${ }^{47}$

Research on the effect of HAART treatment of HIV positive patients with acute psychotic and/or manic symptoms is needed. In a recent pilot study ${ }^{125}, 42$ HIV positive patients with psychiatric symptoms at the University of Cape Town, were given HAART (stavudine and lamivudine with nevirapine or efavirenz). The dominating psychiatric manifestations were sub-acute delirium/organic affective psychosis. These patients 
had a high prevalence of multiple hallucinations, severe thought disorder, movement abnormalities, attention deficits, disorientation, subcortical cognitive impairment and symptom fluctuation. In addition, some patients had severe depression. Most of the patients responded very well to HAART. 16 patients were followed closely for 6 months, and showed a dramatic improvement in their psychiatric symptoms after 6-8 weeks on HAART. Furthermore, CD4 increased from $66.5 \mathrm{cell} s / \mathrm{mm}^{3}$ at baseline to $256 \mathrm{cell} \mathrm{s} / \mathrm{mm}^{3}$ at 6 months. In addition to HAART, the patients were also given antipsychotic drug treatment, but more specific details of the treatment regime are not given in the report. Another study indicate that a CNS-penetrating antiretroviral (zidovudine) offer some protection against secondary mania. ${ }^{74}$

\section{Conclusion}

The use and distribution of HAART is steadily increasing outside the western world. The positive effects of HAART on HIV disease are well documented. HAART has also decreased the incidence of $\mathrm{HAD}$, but does not give complete protection from this condition. To be able to follow and understand the clinical course of $\mathrm{HAD}$, including possible subtypes, it will be important for future research to focus on the development of new biomarkers. ${ }^{21}$ There is also a need to determine the prevalence and development of HIV-associated neurocognitive impairment and other CNS complications of HIV, as well as confounders and co morbidities ${ }^{57}$, in patients who are receiving HAART. ${ }^{11,57}$ The therapeutic efficacy of HAART in the CNS is dependent at least in part upon its ability to achieve inhibitory drug concentrations. Therefore, finding new means of allowing drugs to cross the BBB and gain access to the CNS is critical for treatment of $\mathrm{HAD}$ and elimination of the brain as a potential viral reservoir., ${ }^{3,2} 1$ A better understanding of the pathogenesis of $\mathrm{HAD}$ is also needed to identify additional therapeutic strategies for the prevention and treatment of this neurodegenerative disease. The mechanism of HIV entry in the CNS, the pathological and neurotoxic events that occur in response to HIV CNS infection and the mechanism of viral evolution within the CNS should be further elucidated. ${ }^{3,9}$ Also, well designed clinical trials are required to gain a better understanding of how to treat HIV patients with psychotic and affective symptoms effectively and in safety.

\section{References}

1. Scaravilli F, Bazille C, Gray F. Neuropathologic contributions to understandning AIDS and the central nervous system. Brain Pathol 2007;1 17(2):197-208

2. Reeves JD, Doms RW. Human immunodeficiency virus type 2.J Gen Virol 2002;83(Pt 6):1253-65.

3. Albright AV, Soldan SS, González-Scarano F. Pathogenesis of human immunodeficiency virus-induced neurological disease. J Neurovirol 2003;9(2):222-27.

4. Anthony IC, Arango JC, Stephens B, Simmonds P, Bell JE. The effects of illicit drugs on the HIV infected brain. Front Biosci 2008;13:12941307.

5. Adams MA, Ferraro FR. Acquired immunodeficiency syndrome dementia complex. J Clin Psychol 1997;53(7):767-78.

6. Anthony IC, Bell JE. The Neuropathology of HIVIAIDS. Int Rev Psychiatry 2008;20(1):15-24.

7. Hult B, Chana G, Masliah E, Everall I. Neurobiology of HIV. Int Rev Psychiatry 2008;20(1):3-13.
8. Koutsilieri E, Scheller C, Sopper S, ter Meulen $V$, Riederer P. The pathogenesis of HIV-induced dementia. Mech Ageing Dev 2002;123(8):1047-53.

9. Kaul M, Lipton SA. Mechanisms of neuroimmunity and neurodegeneration associated with HIV-1 infection and AIDS.J Neuroimmune Pharmacol 2006; 1 (2):138-51.

10. Sharer LR. Pathology of HIV-1 infection of the central nervous system. A review. J Neuropathol Exp Neurol 1992;51 (1):3-11.

11. MCArthur JC, Haughey N, Gartner S, Conant K, Pardo C, Nath A, Sacktor N. Human immunodeficiency virus-associated dementia: an evolving disease. J Neurovirol 2003;9(2):205-21.

12. Lawrence DM, Durham LC, Schwartz L, Seth P, Maric D, Major EO. Human immunodeficiency virus type 1 infection of human brainderived progenitor cells. J Virol 2004;78(14):7319-28

13. Kaul M. HIV's double strike at the brain: neuronal toxicity and compromised neurogenesis. Front Biosci 2008; 13:2484-94.

14. Loewenstein RJ, Sharfstein SS. Neuropsychiatric aspects of acquired immune deficiency syndrome. Int J Psychiatry Med 1983$1984 ; 13(4): 255-60$

15. Navia BA, Jordan BD, Price RW. The AIDS dementia complex: I. Clinical features. Ann Neurol 1986;19(6):517-24.

16. Felgenhauer $K$. Another venereal disease with frequent nervous system involvement: neuro-AIDS. J Neurol 1987;234(2):65-6.

17. Thomas CS, Szabadi E. Paranoid psychosis as the first presentation of a fulminating lethal case of AIDS. Br J Psychiatry 1987; 151:693-5.

18. Price RW, Brew B, Sidtis J, Rosenblum M, Scheck AC, Cleary P. The brain in AIDS: central nervous system HIV-1 infection and AIDS dementia complex. Science 1988; 239(4840):586-92.

19. Janssen RS, Cornblath DR, Epstein LG, et al. Nomenclature and research case definitions for neurological manifestations of human immunodeficiency virus type-1 (HIV-1) infection. Report of a working group of the American Academy of Neurology AIDS Task Force. Neurology 1991;41(6):778-85.

20. Antinori A, Arendt G, Becker JT, Brew BJ, Byrd DA, Cherner M, Clifford DB, Cinque P, Epstein LG, Goodkin K, Gisslen M, Grant I, Heaton RK, Joseph J, Marder K, Marra CM, MCArthur JC, Nunn M, Price RW, Pulliam L, Robertson KR, Sacktor N, Valcour V, Wojna VE. Updated research nosology for HIV-associated neurocognitive disorders. Neurology 2007;69(18):1789-99.

21. Nath A, Schiess N, Venkatesan A, Rumbaugh J, Sacktor N, McArthur J. Evolution of HIV dementia with HIV infection. Int Rev Psychiatry 2008;20(1):25-31.

22. von Giesen HJ, Haslinger BA, Rohe S, Köller H, Arendt G. HIV Dementia Scale and psychomotor slowing - the best methods in screening for neuro-AIDS. J Neuropsychiatry Clin Neurosci 2005; 17(2):185-91

23. Koutsilieri E, Sopper S, Scheller C, ter Meulen V, Riederer P. Parkinsonism in HIV dementia. J Neural Transm 2002;109(5-6):76775.

24. Reger M, Welsh R, Razani J, Martin DJ, Boone KB. A meta-analysis of the neuropsychological sequelae of HIV infection. J Int Neuropsychol Soc 2002;8(3):410-24.

25. Arendt G, Hefter $H$, Hilperath F, von Giesen HJ, Strohmeyer G, Freund HJ. Motor analysis predicts progression in HIV-associated brain disease. J Neurol Sci 1994;123(1-2):180-5.

26. Dunlop O, Björklund R, Bruun JN, Evensen R, Goplen AK, Liestöl K, Sannes M, Maehlen J, Myrvang B. Early psychomotor slowing predicts the development of HIV dementia and autopsy-verified HIV encephalitis. Acta Neurol Scand 2002;105(4):270-5.

27. Samuelsson K, Pirskanen-Matell R, Bremmer S, Hindmarsh T, Nilsson BY, Persson HE. The nervous system in early HIV infection: a 
prospective study through 7 years. Eur J Neurol 2006;13:283-91.

28. Ellis RJ, Moore DJ, Childers ME, Letendre S, McCutchan JA, Wolfson T, Spector SA, Hsia K, Heaton RK, Grant I. Progression to neuropsychological impairment in human immunodeficiency virus infection predicted by elevated cerebrospinal fluid levels of human immunodeficiency virus RNA. Arch Neurol 2002;59(6):923-8.

29. Verma A, Berger JR. ALS syndrome in patients with HIV-1 infection.J Neurol Sci 2006;240(1-2):59-64.

30. Keswani SC, Pardo CA, Cherry CL, Hoke A, McArthur JC. HIVassociated sensory neuropathies. AIDS 2002;16(16):2105-17.

31. Estanislao L, Thomas D, Simpson D. HIV neuromuscular disease and mitochondrial function. Mitochondrion 2004;4(2-3):131-9.

32. Sacktor NC, Wong M, Nakasujja N, Skolasky RL, Selnes OA, Musisi S, Robertson K, McArthur JC, Ronald A, Katabira E. The International HIV Dementia Scale: a new rapid screening test for HIV dementia. AIDS 2005;19(13):1367-74.

33. Power C, Selnes OA, Grim JA, McArthur JC. HIV Dementia Scale: a rapid screening test. J Acquir Immune Defic Syndr Hum Retrovirol 1995;8(3):273-8.

34. Ganasen KA, Fincham D, Smit J, Seedat S, Stein D. Utility of the HIV Dementia Scale (HDS) in identifying HIV dementia in a South African sample. J Neurol Sci 2008;269(1-2):62-4.

35. Bottiggi KA, Chang JJ, Schmitt FA, Avison MJ, Mootoor Y, Nath A, Berger JR. The HIV Dementia Scale: predictive power in mild dementia and HAART.J Neurol Sci 2007; 260(1-2):1 1-5.

36. Evers S, Rahmann A, Schwaag S, Frese A, Reichelt D, Husstedt IW. Prevention of AIDS dementia by HAART does not depend on cerebrospinal fluid drug penetrance. AIDS Res Hum Retroviruses 2004;20(5):483-91.

37. Sacktor N, McDermott MP, Marder K, Schifitto G, Selnes OA, McArthur JC, Stern Y, Albert S, Palumbo D, Kieburtz K, De Marcaida JA, Cohen B, Epstein L. HIV-associated cognitive impairment before and after the advent of combination therapy. J Neurovirol 2002;8(2):136-42.

38. Maj M, Satz P, Janssen R, Zaudig M, Starace F, D'Elia L, Sughondhabirom B, Mussa M, Naber D, Ndetei D, et al. WHO Neuropsychiatric AIDS study, cross-sectional phase II. Neuropsychological and neurological findings. Arch Gen Psychiatry 1994;51 (1):51-61.

39. Sacktor N, Nakasujja N, Robertson K, Clifford DB. HIV-associated cognitive impairment in sub-Saharan Africa - the potential effect of clade diversity. Nat Clin Pract Neurol 2007;3(8):436-43

40. Howlett WP, Nkya WM, Mmuni KA, Missalek WR. Neurological disorders in AIDS and HIV disease in the northern zone of Tanzania. AIDS 1989;3(5):289-96

41. Perriëns JH, Mussa M, Luabeya MK, Kayembe K, Kapita B, Brown C Piot P, Janssen R. Neurological complications of HIV-1-seropositive internal medicine inpatients in Kinshasa, Zaire.J Acquir Immune Defic Syndr 1992;5(4):333-40.

42. Wong MH, Robertson K, Nakasujja N, Skolasky R, Musisi S, Katabira E, McArthur JC, Ronald A, Sacktor N. Frequency of and risk factors for HIV dementia in an HIV clinic in sub-Saharan Africa. Neurology 2007;68(5):350-5

43. Salawu FK, Bwala SA, Wakil MA, Bani B, Bukbuk DN, Kida I. Cognitive function in HIV-seropositive Nigerians without AIDS.J Neurol Sci 2008;267(1-2):142-6.

44. Clifford DB, Mitike MT, Mekonnen Y, Zhang J, Zenebe G, Melaku Z, Zewde A, Gessesse N, Wolday D, Messele T, Teshome M, Evans S. Neurological evaluation of untreated human immunodeficiency virus infected adults in Ethiopia. J Neurovirol 2007;13(1):67-72

45. Joska JA, Fincham DS, Stein DJ, Paul RH, Seedat S. Clinical correlates of HIV-associated neurocognitive disorders in South Africa. AIDS Behav 2009;Mar 27 (Epub ahead of print)

46. Rao VR, Sas AR, Eugenin EA, Siddappa NB, Bimonte-Nelson H, Berman JW, Ranga U, Tyor WR, Prasad VR. HIV-1 clade-specific differences in the induction of neuropathogenesis. J Neurosci 2008;28(40):10010-6.

47. Dubé B, Benton T, Cruess DG, Evans DL. Neuropsychiatric manifestations of HIV infection and AIDS.J Psychiatry NeurosCi 2005;30(4):237-46.

48. Treisman G, Angelino A. Interrelation between psychiatric disorders and the prevention and treatment of HIV infection. Clin Infect Dis 2007;45 Suppl 4:S313-7.

49. Atkinson JH Jr, Grant I, Kennedy CJ, Richman DD, Spector SA, McCutchan JA. Prevalence of psychiatric disorders among men infected with human immunodeficiency virus: a controlled study. Arch Gen Psychiatry 1988;45(9):859-64.

50. Hinkin CH, Castellon SA, Atkinson JH, Goodkin K. Neuropsychiatric aspects of HIV infection among older adults. J Clin Epidemiol 2001;54 Suppl 1: S44-52.

51. Olley BO, Gxamza F, Seedat S, Theron H, Taljaard J, Reid E, Reuter H, Stein DJ. Psychopathology and coping in recently diagnosed HIVIAIDS patients - the role of gender. S Afr Med J 2003;93(12):928-31.

52. Judd F, Komiti A, Chua P, Mijch A, Hoy J, Grech P, Street A, Lloyd J, Williams B. Nature of depression in patients with HIVIAIDS. Aust N Z J Psychiatry 2005;39(9):826-32.

53. Morrison MF, Petitto JM, Ten Have T, Gettes DR, Chiappini MS, Weber AL, Brinker-Spence P, Bauer RM, Douglas SD, Evans DL Depressive and anxiety disorders in women with HIV infection. Am J Psychiatry 2002;159(5):789-96.

54. Alciati A, Gallo L, Monforte AD, Brambilla F, Mellado C. Major depression-related immunological changes and combination antiretroviral therapy in HIV-seropositive patients. Hum Psychopharmacol 2007;22(1):33-40.

55. Evans DL, Ten Have TR, Douglas SD, Gettes DR, Morrison M et al. Association of depression with viral load, CD8 T lymphocytes and natural killer cells in women with HIV infection. Am J Psychiatry 2000; 159(10):1752-9.

56. Ickovics JR, Hamburger ME, Vlahov D, Schoenbaum EE, Schuman P, Boland RJ, Moore J; HIV Epidemiology Research Study Group. Mortality, CD4 cell count decline, and depressive symptoms among HIV-seropositive women: longitudinal analysis from the HIV Epidemiology Research Study. JAMA 2001;285(11):1466-74.

57. Wojna $V$, Nath $A$. Challenges to the diagnosis and management of HIV dementia. AIDS Read 2006;16(11):615-6, 621-4, 626, 629-32.

58. Gibbie T, Mijch A, Ellen S, Hoy J, Hutchison C, Wright E, Chua P, Judd F. Depression and neurocognitive performance in individuals with HIVIAIDS: 2-year follow-up. HIV Med 2006;7(2):1 12-21.

59. Castellon SA, Hardy DJ, Hinkin CH, Satz P, Stenquist PK, van Gorp WG, Myers HF, Moore L. Components of depression in HIV-1 infection: their differential relationship to neurocognitive performance. J Clin Exp Neuropsychol 2006;28(3):420-37.

60. von Giesen HJ, Bäcker R, Hefter H, Arendt G. Depression does not influence basal ganglia-mediated psychomotor speed in HIV-1 infection. J Neuropsychiatry Clin Neurosci 2001;13(1):88-94.

61. Olley BO, Zeier MD, Seedat S, Stein DJ. Post-traumatic stress disorder among recently diagnosed patients with HIVIAIDS in South Africa. AIDS Care 2005;17(5):550-7.

62. Repetto MJ, Petitto JM. Psychopharmacology in HIV-infected patients. Psychosom Med 2008;70(5):585-92.

63. Tseng AL, Foisy MM. Significant interactions with new antiretrovirals 
and psychotropic drugs. Ann Pharmacother 1999;33(4):461-73.

64. DeSilva KE, Le Flore DB, Marston BJ, Rimland D. Serotonin syndrome in HIV-infected individuals receiving antiretroviral therapy and fluoxetine. AIDS 2001;15(10):1281-5.

65. Elliott AJ, Roy-Byrne PP. Mirtazapine for depression in patients with human immunodeficiency virus. J Clin Psychopharmacol 2000;20(2):265-7

66. Sewell MC, Goggin KJ, Rabkin JG, Ferrando SJ, McElhiney MC, Evans S. Anxiety syndromes and symptoms among men with AIDS. Psychosomatics 2000;41(4):294-300.

67. Perretta P, Nisita C, Zaccagnini E, Lorenzetti C, Nuccorini A, Cassano GB, Akiskal HS. Psychopathology in 90 consecutive human immunodeficiency virus-seropositive and acquired immune deficiency syndrome patients with mostly intravenous drug use history. Compr Psychiatry 1996;37(4):267-72.

68. Kelly B, Raphael B, Judd F, Kernutt G, Burnett P, Burrows G. Posttraumatic stress disorder in response to HIV infection. Gen Hosp Psychiatry 1998;20(6):345-52.

69. Nakimuli-Mpungu E, Musisi S, Mpungu SK, Katabira E. Primary mania versus HIV-related secondary mania in Uganda. Am J Psychiatry 2006;163(8):1349-54.

70. Kieburtz K, Zettelmaier, AE, Ketonen L, Tuite M, Caine ED. Manic syndrome in AIDS. Am J Psychiatry 1991;148(8):1068-70.

71. Ellen SR, Judd FK, Mijch AM, Cockram A. Secondary mania in patients with HIV infection. Aust N Z J Psychiatry 1999;33(3):353-60

72. Lyketsos CG, Hanson AL, Fishman M, Rosenblatt A, McHugh PR, Treisman GJ. Manic syndrome early and late in the course of HIV. Am J Psychiatry 1993;150(2):326-7.

73. Lyketsos CG, Schwartz J, Fishman M, Treisman G. AIDS mania.J Neuropsychiatry Clin Neurosci 1997;9(2):277-9

74. Mijch AM, Judd FK, Lyketsos CG, Ellen S, Cockram A. Secondary mania in patients with HIV infection: are antiretrovirals protective? J Neuropsychiatry Clin Neurosci. 1999;1 1 (4):475-480.

75. Krauthammer C, Klerman GL. Secondary mania: manic syndromes associated with antecedent physical illness or drugs. Arch Gen Psychiatry 1978;35(11):1333-9

76. Hare CB. WHO Staging System for HIV Infection and Disease in Adolescents and Adults, Table 3; Clinical Overview of HIV Disease. In: Peiperl L, Coffey S, Volberding PA, eds. HIV InSite Knowledge Base [textbook online]. San Francisco: UCSF Center for HIV Information; 2006. Accessed March 23, 2006. Available online at http://hivinsite.ucsf.edu/InSite?page=kb-03-01-01.

77. Letendre SL, Woods SP, Ellis RJ, Atkinson JH, Masliah E, van den Brande G, Durelle J, Grant I, Everall I; HNRC Group. Lithium improves HIV-associated neurocognitive impairment. AIDS 2006;20(14):1885-8

78. Schifitto G, Peterson DR, Zhong J, Ni H, Cruttenden $K$, Gaugh $M$, Gendelman HE, Boska M, Gelbard H. Valproic acid adjunctive therapy for HIV-associated cognitive impairment: a first report. Neurology 2006;66(6):919-21.

79. Parenti DM, Simon GL, Scheib RG, Meyer WA 3rd, Sztein MB, Paxton H, DiGioia RA, Schulof RS. Effect of lithium carbonate in HIV-infected patients with immune dysfunction.J Acquir Immune Defic Syndr 1988;1 (2):119-24

80. Simpson DM, MCArthur JC, Olney R, Clifford D, So Y, Ross D, Baird BJ, Barrett P, Hammer AE; Lamotrigine HIV Neuropathy Study Team. Lamotrigine for HIV-associated painful sensory neuropathies: a placebo-controlled trial. Neurology 2003;60(9):1508-14.

81. van der Lee MJ, Dawood L, ter Hofstede HJ, de Graaff-Teulen MJ, van Ewijk-Beneken Kolmer EW, Caliskan-Yassen N, Koopmans PP, Burger DM. Lopinavir/ritonavir reduces lamotrigine plasma concentrations in healthy subjects. Clin Pharmacol Ther 2006;80(2):159-68.

82. Berbel Garcia A, Latorre Ibarra A, Porta Etessam J, Martinez Salio A Perez Martinez D, Siaz Diaz, Toledo Heras M. Protease inhibitorinduced carbamazepine toxicity. Clin Neuropharmacol 2000;23(4):216-8.

83. Dolder CR, Patterson TL, Jeste DV. HIV, psychosis and aging: past, present and future. AIDS 2004;18 Suppl 1:S35-S42.

84. Cournos F, McKinnon K. HIV seroprevalence among people with severe mental illness in the United States: a critical review. Clin Psychol Rev 1997;17(3):259-69.

85. Cournos F, McKinnon K, Sullivan G. Schizophrenia and comorbid human immunodeficiency virus or hepatitis $C$ virus. J Clin Psychiatry 2005;66 Suppl 6:27-33. Review.

86. Sewell DD. Schizophrenia and HIV. Schizophr Bull 1996;22 (3):46573.

87. de Ronchi D, Faranca I, Forti P, Ravaglia G, Borderi M, Manfredi R, Volterra V. Development of acute psychotic disorders and HIV-1 infection. Int J Psychiatry Med 2000;30(2):173-83.

88. Navia BA, Price RW. The acquired immunodeficiency syndrome dementia complex as the presenting or sole manifestation of human immunodeficiency virus infection. Arch Neurol 1987;44(1):65-9.

89. Sewell DD, Jeste DV, Atkinson JH, Heaton RK, Hesselink JR, Wiley C, Thal L, Chandler JL, Grant I. HIV-associated psychosis: a study of 20 cases. San Diego HIV Neurobehavioral Research Center Group. Am J Psychiatry 1994;151 (2):237-42

90. Kelly DV, Béique LC, Bowmer MI. Extrapyramidal symptoms with ritonavirlindinavir plus risperidone. Ann Pharmacother 2002;36(5):827-30

91. Lee SI, Klesmer J, Hirsch BE. Neuroleptic malignant syndrome associated with use of risperidone, ritonavir, and indinavir: a case report. Psychosomatics 2000;41 (5):453-4

92. Chander G, Himelhoch S, Moore RD. Substance abuse and psychiatric disorders in HIV-positive patients: epidemiology and impact on antiretroviral therapy. Drugs 2006;66(6):769-89.

93. Dougherty RH, Skolasky RL Jr, MCArthur JC. Progression of HIVassociated dementia treated with HAART. AIDS Read 2002;12(2):69-74

94. Temesgen Z, Warnke D, Kasten MJ. Current status of antiretroviral therapy. Expert Opin Pharmacother 2006;1(12):1541-54.

95. http//www.who.int/hiv/pub/prev_care/en/arvrevision2003en.pdf. WHO guidelines. Scaling up antiretroviral therapy in resourcelimited settings: treatment guidelines for a public health approach (2003).

96. http://www. who.int/hiv/pub/guidelines/artadultguidelines.pdf. WHO guidelines. Antiretroviral therapy for HIV infection in adults and adolescents: recommendations for a public health approach (2006 revision)

97. Altmann A, Rosen-Zvi M, Prosperi M, Aharoni E, Neuvirth $H$, Schülter E, Büch J, Struck D, Peres Y, Incardona F, Sönnerborg A, Kaiser R, Zazzi M, Lengauer T. Comparison of classifier fusion methods for predicting response to anti HIV-1 therapy. PLOS ONE 2008;3(10): e3470. doi:10.1371/journal.pone.0003470

98. Rihs TA, Begley K, Smith DE, Sarangapany J, Callaghan A, Kelly M, Post JJ, Gold J. Efavirenz and chronic neuropsychiatric symptoms: a cross-sectional case control study. HIV Med 2006;7(8):544-8.

99. Robertson J, Meier M, Wall J, Ying J, Fichtenbaum CJ. Immune reconstitution syndrome in HIV: validating a case definition and identifying clinical predictors in persons initiating antiretroviral therapy. Clin Infect Dis 2006;42(11):1639-46. 
100. Sacktor N, Lyles RH, Skolasky R, Kleeberger C, Selnes OA, Miller EN, Becker JT, Cohen B, MCArthur JC; Multicenter AIDS Cohort Study. HIV-associated neurologic disease incidence changes: Multicenter AIDS Cohort Study, 1990-1998. Neurology 2001;56(2):257-60.

101. Bhaskaran K, Mussini C, Antinori A, Walker AS, Dorrucci M, Sabin C, Phillips A, Porter K; CASCADE Collaboration. Changes in the incidence and predictors of human immunodeficiency virusassociated dementia in the era of highly active antiretroviral therapy. Ann Neurol 2008;63(2).213-21.

102. Sacktor NC, Lyles RH, Skolasky RL, Anderson DE, McArthur JC, McFarlane G, Selnes OA, Becker JT, Cohen B, Wesch J, Miller EN. Combination antiretroviral therapy improves psychomotor speed performance in HIV-seropositive homosexual men. Multicenter AIDS Cohort Study (MACS). Neurology 1999;52(8): 1640-7.

103. Robertson KR, Robertson WT, Ford S, Watson D, Fiscus S, Harp AG, Hall CD. Highly active antiretroviral therapy improves neurocognitive functioning. J Acquir Immune Defic Syndr 2004;36(1):562-6.

104. Robertson K, Kopnisky K, Hakim J, Merry C, Nakasujja N, Hall C, Traore M, Sacktor N, Clifford D, Newton C, Van Rie A, Holding P, Clements J, Zink C, Mielke J, Hosseinipour M, Lalloo U, Amod F, Marra C, Evans S, Liner J; Second Assessment of NeuroAIDS in Africa Conference Participants. Second assessment of NeuroAIDS in Africa. J Neurovirol 2008; 14(2):89-101.

105. Clements JE, Li M, Gama L, Bullock B, Carruth LM, Mankowski JL, Zink MC. The central nervous system is a viral reservoir in simian immunodeficiency virus-infected macaques on combined antiretroviral therapy: a model for human immunodeficiency virus patients on highly active antiretroviral therapy. J Neurovirol 2005; 11 (2):180-9

106. Antinori A, Giancola ML, Grisetti S, Soldani F, Alba L, Liuzzi G, Amendola A, Capobianchi M, Tozzi V, Perno CF. Factors influencing virological response to antiretroviral drugs in cerebrospinal fluid of advanced HIV-1-infected patients. AIDS 2002;16(14):1867-76.

107. Letendre SL, MCCutchan JA, Childers ME, Woods SP, Lazzaretto D, Heaton RK, Grant I, Ellis RJ; HNRC Group. Enhancing antiretroviral therapy for human immunodeficiency virus cognitive disorders. Ann Neurol 2004;56(3):416-23.

108. Letendre S, Marquie-Beck J, Capparelli E, Best B, Clifford D, Collier AC, Gelman BB, MCArthur JC, McCutchan JA, Morgello S, Simpson D, Grant I, Ellis RJ; CHARTER Group. Validation of the CNS PenetrationEffectiveness rank for quantifying antiretroviral penetration into the central nervous system. Arch Neurol 2008;65(1):65-70.

109. Giancola ML, Lorenzini P, Balestra P, Larussa D, Baldini F, Corpolongo A, Narciso P, Bellagamba R, Tozzi V, Antinoria A. Neuroactive antiretroviral drugs do not influence neurocognitive performance in less advanced HIV-infected patients responding to highly active antiretroviral therapy. J Acquir Immune Defic Syndr 2006;41 (3):332-7.

110. Valcour V, Paul R. HIV infection and dementia in older adults. Clin Infect Dis 2006;42(10):1449-54.

111. Cysique LA, Maruff P, Brew BJ. Prevalence and pattern of neuropsychological impairment in human immunodeficiency virusinfectedlacquired immunodeficiency syndrome (HIVIAIDS) patients across pre- and post-highly active antiretroviral therapy eras: a combined study of two cohorts. J Neurovirol 2004;10(6):350-7.

112. Sacktor N, Nakasujja N, Skolasky R, Robertson K, Wong M, Musisi S,
Ronald A, Katabira E. Antiretroviral therapy improves cognitive impairment in HIV+ individuals in sub-Saharan Africa. Neurology 2006;67(2):311-4

113. Sacktor N, Skolasky R, Selnes OA, Watters M, Poff P, Shiramizu B, Shikuma $C$, Valcour V. Neuropsychological test profile differences between young and old human immunodeficiency virus-positive individuals. J Neurovirol 2007;13(3):203-9.

1 14. Mellgren Å, Antinori A, Cinque P, Price RW, Eggers C, Hagberg L, Gisslén M. Cerebrospinal fluid HIV-1 infection usually responds well to antiretroviral treatment. Antivir Ther 2005;10(6):701-7.

115. Eggers C, Hertogs K, Stürenburg HJ, van Lunzen J, Stellbrink HJ. Delayed central nervous system virus suppression during highly active antiretroviral therapy is associated with HIV encephalopathy, but not with viral drug resistance or poor central nervous system drug penetration. AIDS 2003;17(13):1897-906.

116. Bandaru VV, McArthur JC, Sacktor N, Cutler RG, Knapp EL, Mattson MP, Haughey NJ. Associative and predicitive biomarkers of dementia in HIV-1-infected patients. Neurology 2007;68(18):1481-7.

117. Cysique LA, Brew BJ, Halman M, Catalan J, Sacktor N, Price RW, Brown S, Atkinson JH, Clifford DB, Simpson D, Torres G, Hall C, Power C, Marder K, McArthur JC, Symonds W, Romero C. Undetectable cerebrospinal fluid HIV RNA and beta-2-microglobulin do not indicate inactive AIDS dementia complex in highly active antiretroviral therapy-treated patients. J Acquir Immune Defic Syndr 2005;39(4):426-9.

1 18. Gisslen M, Hagberg L, Brew BJ, Cinque P, Price RW, Rosengren L. Elevated cerebrospinal fluid neurofilament light protein concentrations predict the development of AIDS dementia complex. $J$ Infect Dis 2007; 195(12):1774-8.

11 9. Brew BJ, Pemberton L, Blennow K, Wallin A, Hagberg L. CSF amyloid beta42 and tau levels correlate with AIDS dementia complex. Neurology 2005;65(9):1490-2.

120. Anthony IC, Ramage SN, Carnie FW, Simmonds P, Bell JE. Influence of HAART on HIV-related CNS disease and neuroinflammation.J Neuropathol Exp Neurol 2005;64(6):529-36.

121. Ances BM, Letendre SL, Alexander T, Ellis RJ. Role of psychiatric medications as adjunct therapy in the treatment of HIV associated neurocognitive disorders. Int Rev Psychiatry 2008;20(1):89-93.

122. Everall IP, Bell C, Mallory M, Langford D, Adame A, Rockestein E, Masliah E. Lithium ameliorates HIV-gp120-mediated neurotoxicity. Mol Cell Neurosci 2002;21 (3):493-501.

123. Schifitto G, Navia BA, Yiannoutsos CT, Marra CM, Chang L, Ernst T, Jarvik JG, Miller EN, Singer EJ, Ellis RJ, Kolson DL, Simpson D, Nath A, Berger J, Shriver SL, Millar LL, Colquhoun D, Lenkinski R, Gonzalez RG, Lipton SA the Adult AIDS Clinical Trial Group (ACTG) 301 and 700 Teams and the HIV MRS Consortium. Memantine and HIVassociated cognitive impairment: a neuropsychological and proton magnetic resonance spectroscopy study. AIDS 2007;21 (14):18771886.

124. Rabkin JG, McElhiney MC, Rabkin R, Ferrando SJ. Modafinil treatment for fatigue in HIV+ patients: a pilot study. J Clin Psychiatry 2004;65(12):1688-95.

125. Saunders J. Report on the provincial government of the Western Cape/University of the Western Cape neuropsychiatric HIV study. 2006 Oct.:1-24. 